\title{
Utility of temporally distinct baculovirus promoters for constitutive and baculovirus-inducible transgene expression in transformed insect cells
}

\author{
Chi-Hung Lin and Donald L. Jarvis ${ }^{a}$ \\ Department of Molecular Biology, University of Wyoming, 1000 E. University Avenue, Laramie, \\ WY 82071
}

\section{Abstract}

Genetically transformed lepidopteran insect cell lines have biotechnological applications as constitutive recombinant protein production platforms and improved hosts for baculovirusmediated recombinant protein production. Insect cell transformation is often accomplished with a DNA construct(s) encoding a foreign protein(s) under the transcriptional control of a baculovirus immediate early promoter, such as the ie 1 promoter. However, the potential utility of increasingly stronger promoters from later baculovirus gene classes, such as delayed early (39K), late ( $p 6.9)$, and very late (polh), has not been systematically assessed. Hence, we produced DNA constructs encoding secreted alkaline phosphatase (SEAP) under the transcriptional control of each of the four temporally distinct classes of baculovirus promoters, used them to transform insect cells, and compared the levels of SEAP RNA and protein production obtained before and after baculovirus infection. The ie 1 construct was the only one that supported SEAP protein production by transformed insect cells prior to baculovirus infection, confirming that only immediate early promoters can be used to isolate transformed insect cells for constitutive recombinant protein production. However, baculovirus infection activated transgene expression by all four classes of baculovirus promoters. After infection, cells transformed with the very late (polh) and late ( $p 6.9)$ promoter constructs produced the highest levels of SEAP RNA, but only low levels of SEAP protein. Conversely, cells transformed with the immediate early (iel) and delayed early (39K) promoter constructs produced lower levels of RNA, but equal or higher levels of SEAP protein. Unexpectedly, the $39 \mathrm{~K}$ promoter construct provided tightly regulated, baculovirus-inducible protein production at higher levels than the later promoter constructs. Thus, this study demonstrated the utility of the $39 \mathrm{~K}$ promoter for insect cell engineering, particularly when one requires higher levels of effector protein production than obtained with iel and/or when constitutive transgene expression adversely impacts host cell fitness and/or genetic stability.

\section{Keywords}

Baculovirus-insect cell system; Genetic transformation; Baculovirus promoters; Inducible foreign gene expression; Host improvement; Cell engineering

\footnotetext{
(C) 2013 Elsevier B.V. All rights reserved.

${ }^{a}$ To whom correspondence should be addressed: Tel: 307-766-4282, Fax: 307-766-5098, dljarvis@uwyo.edu.

Publisher's Disclaimer: This is a PDF file of an unedited manuscript that has been accepted for publication. As a service to our customers we are providing this early version of the manuscript. The manuscript will undergo copyediting, typesetting, and review of the resulting proof before it is published in its final citable form. Please note that during the production process errors may be discovered which could affect the content, and all legal disclaimers that apply to the journal pertain.
} 


\section{Introduction}

The baculovirus-insect cell expression system is widely used for recombinant protein production (Jarvis, 2009; Kost et al., 2005; Pennock et al., 1984; Smith et al., 1983). The major advantages of this system include its ability to provide high levels of foreign gene expression and eukaryotic protein modifications, such as phosphorylation and glycosylation. Most recombinant baculovirus vectors express the sequence encoding a foreign protein of interest under the control of the strong promoter from the viral polyhedrin (polh) gene, which functions in conjunction with a virus-encoded RNA polymerase complex. This promoter-polymerase combination produces massive amounts of RNA encoding the protein of interest during the very late stage of baculovirus infection. This can lead to high levels of recombinant protein production, although the actual level obtained depends on the specific protein being produced. Generally, baculovirus-infected insect cells appear to produce secretory pathway proteins at 10 to 100 -fold lower levels than nuclear or cytoplasmic proteins. The reason for this is unclear, but one study has shown that the rate and efficiency of recombinant glycoprotein processing decreases with time of infection, suggesting that baculoviruses have an adverse impact on host secretory pathway function (Jarvis and Summers, 1989).

This observation led to efforts to develop transformed insect cells as a new platform for constitutive foreign gene expression in order to eliminate the need to infect the cells with a baculovirus vector (Jarvis et al., 1990). The original approach involved genetic transformation of lepidopteran insect cell lines with expression plasmids encoding a protein of interest under the control of the promoter from a baculovirus immediate early gene, iel, which had been found to be active in uninfected insect cells (Guarino and Summers, 1986). Transformed insect cell lines encoding human tissue plasminogen activator under iel control processed this complex, secretory pathway glycoprotein product more efficiently than insect cells infected with a recombinant baculovirus vector encoding the same product under polh control (Jarvis et al., 1990). In addition, the yields of secreted, functional protein obtained with the transformed or baculovirus-infected insect cell platforms were about the same, despite the fact that iel is a much weaker promoter (Jarvis et al., 1990). Subsequently, a broader selection of expression plasmids was produced, including some in which the ie1 promoter was replaced with the promoter from another baculovirus immediate early gene, ie2 (Hegedus et al., 1998), and some in which a baculovirus hr5 enhancer element was added to stimulate transcription (Jarvis et al., 1996). Ultimately, various insect cell transformation systems were commercialized and insect cell transformation is now recognized as a standard approach for constitutive recombinant protein production. In addition, insect cell transformation has evolved as an approach that can be used to engineer insect cells as improved hosts for baculovirus-mediated recombinant protein production. This latter application is exemplified by genetic transformation of insect cells with higher eukaryotic genes encoding functions that extend their endogenous protein $\mathrm{N}$-glycosylation pathways, which has yielded transgenic insect cell derivatives that can produce recombinant glycoproteins with human-type $N$-glycan structures (Harrison and Jarvis, 2006; Jarvis, 2009).

Baculovirus genes are expressed in a sequential, temporally regulated fashion in which virus-encoded gene products synthesized during an earlier phase of infection activate promoters controlling the expression of other genes in a later phase of infection (Friesen, 1997; Lu and Miller, 1997; Passarelli and Guarino, 2007; Rohrmann, 2011). Immediate early genes such as ie1 (Guarino and Summers, 1987) and ie2 (Carson et al., 1988) are expressed first, independently of newly synthesized viral transcription factors, and their promoters can drive transcription in uninfected lepidopteran insect cells, as noted above. This is followed by the expression of delayed early genes such as $39 \mathrm{~K}$ (Guarino and Smith, 
1990), which require at least some virus-encoded factors for transcriptional activity (Guarino and Summers, 1986). These early phases of baculoviral infection are followed by viral DNA replication, the late phase of infection, and the expression of late genes such as p6.9 (Wilson et al., 1987), which requires a larger number of virus encoded factors and is probably coupled to viral DNA replication (Passarelli and Guarino, 2007). Finally, baculovirus infections also include a very late phase during which the very late genes, such as polh (Hooft van Iddekinge et al., 1983) are hyper-expressed and viral occlusions, which are intracellular particles containing progeny virions, are produced.

The baculovirus iel promoter was used as the transcriptional control element for the original insect cell transformation efforts because it was expected to drive transcription in uninfected lepidopteran insect cells. However, immediate early promoters are also the weakest of all baculovirus promoters and, therefore, provide the lowest levels of transcription. Later baculovirus promoters present attractive alternatives because they are stronger.

Unfortunately, they are inactive in uninfected insect cells, which lack the requisite virusencoded transcription factors. On the other hand, transcription by any baculovirus promoter in a transformed insect cell line should be activated by baculovirus infection, as this would introduce the requisite transcription factors. Indeed, it has been shown that baculovirus infection initially stimulates transgene expression in insect cells transformed by a variety of different ie1 constructs (Aumiller et al., 2012; Hollister and Jarvis, 2001; Hollister et al., 2002; Hollister et al., 1998; Jarvis, 1993). It also has been shown that baculovirus infection induces transgene expression in insect cells transformed with a polh-green fluorescent protein construct, which facilitates the identification of infected cells in baculovirus plaque assays (Hopkins and Esposito, 2009). Finally, it has been shown that baculovirus infection induces transgene expression in insect cells transformed with DNA constructs encoding polyhedrin under the control of the polh promoter, which enables the production of occluded viral progeny during infection with occlusion-negative recombinant baculoviruses (Lopez et al., 2010). Based on these precedents, we presumed that insect cells transformed with delayed early, late, or very late baculovirus promoter constructs would likely express transgenes in a tightly regulated, baculovirus-inducible fashion and at increasingly higher levels, reflecting their relative promoter strengths. This possibility was of great interest to us because, if correct, it would facilitate our insect cell engineering projects. However, a literature search revealed no comprehensive information on the utility of different temporal classes of baculovirus promoters for insect cell transformation for either constitutive foreign gene expression or host cell engineering applications. Thus, we addressed this issue by transforming insect cells with constructs encoding the widely used reporter protein, secreted alkaline phosphatase (SEAP), under the control of four temporally distinct baculovirus promoters, and then measuring SEAP production before and after baculovirus infection. Our results confirmed that only the immediate early baculovirus promoter supported constitutive SEAP production in uninfected, transformed insect cells. They also confirmed that delayed early, late, and very late promoters can provide tightly regulated transgene expression, as each is silent in the absence of infection and activated by baculovirus infection of transformed insect cells. Unexpectedly, our results also showed that insect cells transformed with the $39 \mathrm{~K}$ construct produced the highest levels of SEAP after baculovirus infection, even though the later promoters produced far more RNA. Thus, this study demonstrates that $39 \mathrm{~K}$ and possibly other delayed early promoters have great utility for insect cell engineering, particularly for modifications requiring higher levels of transgene expression than can be obtained with the $i e 1$ promoter and/or when constitutive transgene expression adversely impacts cell fitness and/or genetic stability. 


\section{Materials and methods}

\subsection{Construction of SEAP expression plasmids}

The SEAP open reading frame was PCR-amplified with genomic DNA from a recombinant baculovirus (AcSEAP; Davis et al., 1992) as the template and the product was gel-purified and cloned into pIE1HR3 (Jarvis et al., 1996) to produce pIE1-hr5-SEAP. Subsequently, the $39 K$, p6.9, and polh promoters were PCR-amplified with genomic DNA from Autographa californica multicapsid nucleopolyhedrovirus (AcMNPV) strain E2 as the template using primers that added unique $E c o R I$ and $B g I I$ sites to the $5^{\prime}$ and $3^{\prime}$ ends, respectively. Each amplification product was gel-purified and cloned into EcoRI/BgIII-digested pIE1-hr5SEAP, thereby replacing the $h r 5-i e 1$ enhancer-promoter cassette with the $39 K, p 6.9$, or polh promoters to produce p39K-SEAP, p6.9-SEAP, and pPH-SEAP, respectively. Finally, the AcMNPV hr5 enhancer element was PCR-amplified using pIE1-hr5-SEAP as the template and blunt-end ligated into the repaired EcoRI site of p39K-SEAP, p6.9-SEAP, and pPHSEAP to produce p39K-hr5-SEAP, p6.9-hr5-SEAP, and pPH-hr5-SEAP, respectively. Error-free clones of the final expression constructs were identified by sequencing and used for the remainder of this study.

\subsection{Insect cell transformation}

Sf9 cells were co-transfected with a mixture of pIE1-hygro plus pIE1-hr5-SEAP, p39K-hr5SEAP, p6.9-hr5-SEAP, or pPH-hr5-SEAP and transformed cells were selected for one week in complete TNM-FH medium (Summers and Smith, 1987), which is defined as TNM-FH medium containing 10\% (v/v) fetal bovine serum (Thermo Scientific HyClone, Logan, UT) and 1\% (w/v) pluronic F68 (Sigma Aldrich, St. Louis, MO), supplemented with $1 \mathrm{mg} / \mathrm{mL}$ hygromycin (Sigma Aldrich), as described previously (Harrison and Jarvis, 2007). Surviving cells were washed with fresh TNM-FH and amplified in complete TNM-FH without hygromycin to produce polyclonal transformed insect cell cultures designated Sf-ie1-hr5SEAP, Sf-39K-hr5-SEAP, Sf-6.9-hr5-SEAP, and Sf-PH-hr5-SEAP. The parental Sf9 cells and their transformed derivatives were initially maintained at $28^{\circ} \mathrm{C}$ as suspension cultures in complete TNM-FH, and then each was adapted to grow in serum-free ESF 921 medium (Expression Systems LLC, Woodland, CA) and cells maintained in this latter medium were used for the SEAP expression experiments.

\subsection{SEAP expression and activity assays}

Sf9 cells and the transformed insect cell derivatives were either mock- or AcMNPV-infected at a multiplicity of $\sim 2$ plaque-forming units/cell, as described previously (Hollister and Jarvis, 2001). The infected cells were washed with ESF 921, seeded in fresh ESF 921 into $50 \mathrm{~mL}$ DeLong shake flasks at a density of $1 \times 10^{6} \mathrm{cells} / \mathrm{mL}$, and incubated in a console platform shaker (Forma Model 4580, Marietta, $\mathrm{OH}$ ) set at $125 \mathrm{rpm}$ and $28^{\circ} \mathrm{C}$. At various times, $2.0 \mathrm{~mL}$ samples were taken from each culture, cell densities were measured, and the cells were removed by low speed centrifugation. The cell free supernatants were used to assay SEAP in the extracellular fractions. The cell pellets were washed once with Trisbuffered saline, re-suspended in $0.3 \mathrm{~mL}$ of extraction buffer $(50 \mathrm{mM}$ Tris $\mathrm{pH} 8.0,100 \mathrm{mM}$ $\mathrm{NaCl}$, and $1 \% \mathrm{NP}-40$ ), and incubated on ice for $10 \mathrm{~min}$. The extracts were centrifuged at $13,000 \mathrm{rpm}$ for $10 \mathrm{~min}$ in a micro-centrifuge and the supernatants were used to assay SEAP in the intracellular fractions. SEAP activity assays were performed in triplicate as described previously (Davis et al., 1992). Briefly, $2 \mu \mathrm{L}$ of each sample were added to $0.2 \mathrm{~mL}$ of SEAP assay buffer (1 M diethanolamine, $\mathrm{pH} 9.8$, containing $0.5 \mathrm{mM} \mathrm{MgCl}_{2}$ and $10 \mathrm{mM}$ homoarginine) and the reactions were incubated for $10 \mathrm{~min}$ at $37^{\circ} \mathrm{C}$. Subsequently, $20 \mu \mathrm{L}$ of $120 \mathrm{mM} p$-nitrophenylphosphate (Sigma-Aldrich) were added, the reactions were incubated for $10 \mathrm{~min}$ at $37^{\circ} \mathrm{C}$, and then absorbance was measured at $405 \mathrm{~nm}$ in a plate reader (PerkinElmer Wallac 1420; Turku, Finland). Parallel reactions containing known amounts of calf 
intestinal phosphatase activity (New England Biolabs, Ipswich, MA) were performed to generate a standard curve, which was used to convert the $\mathrm{A}_{405}$ values to units of SEAP activity normalized to $10^{6}$ cells. Finally, samples of each cell-free supernatant and intracellular extract also were analyzed by immunoblotting with rabbit anti-human placental alkaline phosphatase (AbD Serotec, Oxford, UK) as the primary antibody, a mouse antirabbit IgG-alkaline phosphatase conjugate as the secondary antibody, and a standard color reaction, as described previously (Hillar and Jarvis, 2010).

\subsection{RT-PCR}

Separate samples were taken at various times post-infection from the AcMNPV-infected Sf9 and transformed insect cell cultures described above for RNA extractions. The cells were pelleted by low speed centrifugation, washed once with Tris-buffered saline, and then total RNA was extracted from $1 \times 10^{6}$ cells using the TRI Reagent (Life Technologies Corporation, Carlsbad, CA). After treatment with amplification grade DNase I (Life Technologies), the RNA was quantified by spectrophotometry, and then $4 \mu \mathrm{g}$ of total RNA were used for reverse transcription with ThermoScript Reverse Transcriptase (Life Technologies) according to manufacturer's instructions. Duplicate reactions were performed with and without reverse transcriptase to monitor DNA contamination and reaction products with no evidence of DNA contamination were used as templates for PCRs with Taq DNA polymerase (New England Biolabs). A preliminary experiment established that the PCRs were in the linear range for detection of GAPDH and SEAP RNAs with 25 and 30 amplification cycles, respectively. The PCR products were analyzed by $1 \%$ agarose gel electrophoresis and signal intensities were quantified using a GelDoc 1000 imaging system with Quantity One v.4.5.2 software (BioRad Laboratories, Inc., Hercules, CA).

\section{Results}

\subsection{Isolation of transformed insect cells encoding SEAP under the control of temporally distinct baculovirus promoter classes}

To examine the utility of temporally distinct baculovirus promoter classes for insect cell transformation, we constructed a new set of expression plasmids encoding SEAP under the control of AcMNPV immediate early (iel), delayed early (39K), late ( $p 6.9)$, or very late (polh) promoters linked to an AcMNPV enhancer element (hr5). Each expression plasmid was mixed with a separate ie 1 expression plasmid encoding a hygromycin resistance marker and each mixture was then used to co-transfect $\mathrm{Sf} 9$, an established lepidopteran insect cell line widely used as a host for baculovirus expression vectors (Summers and Smith, 1987). After co-transfection, transformed cells were selected for one week in complete TNM-FH containing hygromycin and surviving cells were amplified, as described in Materials and methods. This yielded polyclonal transformed cell cultures designated Sf-ie1-hr5-SEAP, Sf-39K-hr5-SEAP, Sf-6.9-hr5-SEAP, and Sf-PH-hr5-SEAP encoding SEAP under the control of the AcMNPV ie1, 39K, p6.9, or polh promoters, respectively. These cells were adapted to ESF 921, a serum free insect cell medium, and used to assess the ability of each viral promoter to support transgene expression and SEAP production by transformed insect cells with and without baculovirus infection. The ability of each promoter to support SEAP production without baculovirus infection revealed its utility for creating transformed insect cells for recombinant protein production applications. The ability of each to support SEAP production after baculovirus infection revealed its utility for engineering insect cells as improved hosts for baculovirus vectors, as these transformed cell lines would necessarily be infected with one or more baculovirus vectors to induce recombinant protein production. 
3.2. Only the immediate early baculovirus promoter supported transgene expression in uninfected transformed insect cells

Sf9, Sf-ie1-hr5-SEAP, Sf-39K-hr5-SEAP, Sf-6.9-hr5-SEAP, and Sf-PH-hr5-SEAP cells were seeded into shake flasks, incubated in parallel, and samples were taken at various times and used to prepare cell-free supernatants for SEAP activity assays. The results showed that only the cells transformed with the immediate early (iel) construct produced SEAP activity above background levels observed in control samples from the parental cells (Fig. 1). In this experiment, SEAP continued to accumulate in the extracellular fraction from 0-48 hr after cell seeding. We replicated the same general results in other, independent experiments and also found that SEAP activity continued to accumulate up to $72 \mathrm{hr}$ after seeding. We expected the ie1 promoter to support constitutive SEAP production by transformed Sf9 cells in the absence of baculovirus infection because, like other immediate early baculovirus promoters, it can be transcribed at basal levels by cellular transcription factors (Guarino and Summers, 1986). This is why immediate early baculovirus promoters such as ie 1 and ie 2 are commonly used in expression plasmids designed for insect cell transformation (Hegedus et al., 1998; Jarvis et al., 1990; Jarvis et al., 1996). We also expected the baculovirus 39K, p6.9, and polh promoters to be unable to support constitutive SEAP production by uninfected transformed Sf9 cells because each of these viral promoter classes requires virusencoded transcription factors produced during the delayed early, late, and/or very late phases of infection (Friesen, 1997; Lu and Miller, 1997; Passarelli and Guarino, 2007; Rohrmann, 2011). Thus, the direct assessment of all four promoter classes in uninfected, transformed Sf9 cells confirmed our presumptions from previously published information.

\subsection{All four baculovirus promoters supported transgene expression in baculovirus- infected transformed insect cells}

In the next set of experiments, Sf9, Sf-ie1-hr5-SEAP, Sf-39K-hr5-SEAP, Sf-6.9-hr5-SEAP, and Sf-PH-hr5-SEAP cells were infected with AcMNPV, seeded into shake flasks, incubated in parallel, and samples were taken at various times post-infection and used to prepare total RNA for semi-quantitative RT-PCR assays. The results of those assays showed that only the Sf-ie1-hr5- SEAP cells contained detectable levels of SEAP RNA at $2 \mathrm{hr}$ postinfection, Sf-ie1-hr5-SEAP and Sf-39K-hr5-SEAP cells both contained SEAP RNA by $8 \mathrm{hr}$ post-infection, Sf-ie1-hr5-SEAP, Sf-39K-hr5-SEAP, and Sf-6.9-hr5-SEAP cells all contained SEAP RNA by $24 \mathrm{hr}$ post-infection, and all four transformed insect cell types contained SEAP RNA by $48 \mathrm{hr}$ post-infection (Figs. 2A-2B). The Sf-6.9-hr5-SEAP and SfPH-hr5-SEAP cells accumulated much higher levels of SEAP RNA than Sf-ie1-hr5-SEAP and Sf-39K-hr5-SEAP cells by $48 \mathrm{hr}$ post-infection and continued to accumulate SEAP RNA to even higher levels between 48 and $72 \mathrm{hr}$ post-infection. Thus, baculovirus infection induced transgene expression in each transformed insect cell culture with the timing and magnitude expected from the temporal classification of each of the viral promoters. These results suggested that insect cells transformed with the later promoter constructs would produce higher levels of SEAP protein after baculovirus infection.

To assess this possibility, cell free supernatants were isolated from each baculovirusinfected cell culture at various times post-infection and assayed for SEAP activity. Surprisingly, we found that the insect cells transformed with the late and very late promoter constructs produced only low levels of extracellular SEAP activity during the course of infection (Fig. 3A). The Sf-ie1-hr5-SEAP cells produced higher levels of extracellular SEAP activity than the Sf-6.9-hr5-SEAP or Sf-PH-hr5-SEAP cells up to $48 \mathrm{hr}$ post-infection. By $72 \mathrm{hr}$ post-infection, the Sf-6.9-hr5-SEAP cells had produced about the same amount of extracellular SEAP activity as Sf-ie1-hr5-SEAP cells. In contrast, the Sf-PH-hr5-SEAP cells failed to produce as much extracellular SEAP activity during the $72 \mathrm{hr}$ infection period. Strikingly, despite containing less RNA than the Sf-6.9-hr5-SEAP and Sf-PH-hr5-SEAP 
cells at both time points, the Sf-39K-hr5-SEAP cells produced higher levels of extracellular SEAP activity by $48 \mathrm{hr}$ post-infection and 4- to 6-fold more activity by the end of the $72 \mathrm{hr}$ infection period. These cells also produced about 4-fold more extracellular SEAP activity than Sf-ie1-hr5-SEAP cells by $72 \mathrm{hr}$ post-infection. Thus, while the late and very late baculovirus promoters supported the highest levels of transgene expression at the transcriptional level, as expected, cells transformed with those promoter constructs failed to produce correspondingly high amounts of extracellular SEAP activity. In fact, neither the late nor the very late promoter yielded higher levels of extracellular SEAP activity than the weakest (ie1) promoter during the course of transformed Sf9 cell infection. Moreover, the delayed early $39 K$ promoter, which is also relatively weak, yielded significantly higher levels of extracellular SEAP activity.

To examine the possibility that the cells transformed with the late and very late promoter constructs had actually produced high levels of intracellular SEAP, but it was not secreted due to an adverse impact of baculovirus infection on secretory pathway function (Jarvis and Summers, 1989), we also assayed SEAP activity levels in cell lysates from each culture at various times after infection. The results showed that none of the transformed cell cultures contained significant levels of SEAP activity at any time after infection (Fig. 3B; note $~ 10-$ fold lower range of $y$-axis values relative to Fig. 3A). To examine the possibility that cells transformed with the late and very late promoter constructs had actually produced and possibly even secreted high levels of enzymatically inactive SEAP protein, we performed immunoblotting assays on the extracellular and intracellular fractions isolated from all four transformed insect cell cultures at various times after baculovirus infection. The results were consistent with those from the enzyme activity assays, as they showed Sf-39K-hr5-SEAP cells produced the highest levels of extracellular, immunoreactive protein, Sf-ie1-hr5-SEAP produced lower levels than Sf-39K-hr5-SEAP cells beginning at earlier times than Sf-6.9hr5-SEAP and Sf-PH-hr5-SEAP cells, and Sf-6.9-hr5-SEAP, but not Sf-PH-hr5-SEAP cells ultimately produced about as much as the Sf-ie1-hr5-SEAP cells, but not until $72 \mathrm{hr}$ postinfection (Fig. 4). The immunoblotting results also showed that none of the baculovirusinfected transformed insect cell cultures accumulated substantial amounts of immunoreactive SEAP during the course of infection, which was consistent with the virtual absence of SEAP activity in these cell lysates (Fig. 3B). Finally, we performed viable cell counts to examine the possibility that differences in the viabilities of cells transformed with the various promoter constructs after baculovirus infection could account for the observed differences in SEAP production and secretion. The results showed no major differences among the different cell lines, with viabilities ranging from 94-97\%, 94-96\%, 93.5-95.5\%, $85-86.5 \%$, and $60.5-63 \%$ at $18,24,48,72$, and $96 \mathrm{hr}$ post-infection, respectively.

\section{Discussion}

This study provided the first comprehensive, side-by-side assessment of the utility of all four temporally distinct classes of baculovirus promoters for insect cell transformation for constitutive recombinant protein production and host cell engineering applications. As expected, we found that only the immediate early promoter supported transgene expression and protein production by transformed insect cells in the absence of baculovirus infection. These results directly confirmed previous results indicating that immediate early is the only temporal class of baculovirus promoters that can be used to isolate transformed insect cells for constitutive recombinant protein production. Our results also showed that baculovirus infection activated all four classes of viral promoters in transformed insect cells, confirming and extending previous studies demonstrating that polh-based transgene constructs can provide baculovirus-inducible gene expression in transformed insect cells (Hopkins and Esposito, 2009; Lopez et al., 2010). Except for immediate early, each baculoviral promoter class provided tightly regulated expression, with no detectable transgene expression prior to 
baculovirus infection and, unlike other inducible promoters previously used in insect cell systems (Aumiller et al., 2012; Hegedus et al., 1998), this did not require the addition of an antibiotic or metal to the growth medium. Our results also showed that insect cells transformed with very late ( $p o l h)$ and late ( $p 6.9)$ promoter constructs produced relatively low levels of SEAP protein, despite having the highest levels of accumulated RNA after baculovirus infection. This was not due to a secretory pathway defect, as these cells contained virtually no enzymatically active SEAP protein. Nor was this due to the production of dysfunctional protein during infection, as the cells contained only small amounts and the cell-free media contained the expected amounts of immunoreactive SEAP protein when analyzed by immunoblotting. Finally, our results showed that the delayed early (39K) promoter construct provided the highest level of tightly regulated, baculovirusinducible protein production, as compared to any other class of baculovirus promoters. This is the first result demonstrating that the $39 \mathrm{~K}$ and possibly other delayed early baculovirus promoters have great utility for insect cell engineering. In particular, $39 K$-based transgene constructs will be useful for creating improved insect cell lines that do not detectably express their transgenes until after infection with a baculovirus vector, at which time they can be expected to be expressed relatively quickly and to drive effector protein production to higher levels than constructs containing other temporal classes of baculovirus promoters. These features will greatly facilitate certain host cell engineering projects, particularly those requiring higher levels of effector protein production for optimal function and/or tightly regulated gene expression due to adverse impacts of effector proteins on host cell fitness and/or genetic stability.

In addition to providing a concerted analysis of the utility of temporally distinct baculovirus promoters for transgene expression in transformed insect cells, the present results complement previous findings on the utility of temporally distinct baculovirus promoters for baculovirus-mediated foreign gene expression. Those studies have shown that recombinant secretory pathway proteins are more efficiently glycosylated, secreted, and can have higher specific activities when produced with baculovirus vectors encoding the foreign gene under the transcriptional control of temporally earlier promoters. Most of this previous work has focused on the relatively strong p6.9 promoter (Chazenbalk and Rapoport, 1995; Higgins et al., 2003; Kost et al., 1997; Rankl et al., 1994; Sridhar and Hasnain, 1993), but similar results have been obtained with the much weaker ie1 promoter (Jarvis et al., 1996). To date, relatively little has been done to assess the utility of the $39 \mathrm{~K}$ promoter for baculovirusmediated recombinant protein production, though one study showed that a recombinant baculovirus encoding an insect-specific neurotoxin under $39 K$ control killed insects more quickly than one expressing the same neurotoxin under the control of a very late $(p 10)$ promoter (Regev et al., 2006). The results obtained with the $p 6.9$ and ie1 promoters are consistent with the idea that recombinant secretory pathway protein production during earlier phases is an approach that can be used to avoid the adverse impacts of baculovirus infection on cellular secretory pathway function. However, this does not necessarily provide a net practical advantage, as shown in a recent study in which recombinant baculoviruses encoding Western equine encephalitis virus glycoproteins under the control of the ie1, p6.9, or polh promoters yielded approximately the same amounts of glycosylated, secreted products (Toth et al., 2011). In contrast, the present findings showed that insect cells transformed with the earlier, weaker $39 K$ promoter produced more SEAP than those transformed with the later, stronger $p 6.9$ and polh promoter constructs after baculovirus infection. Future studies are needed to determine if these same results will be obtained with other secreted glycoproteins or, for that matter, with other types of proteins, such as membrane bound and intracellular proteins. In addition, it will be interesting to assess the mechanism underlying the disconnect observed in this study between the levels of SEAP RNA and protein produced after baculovirus infection of insect cells transformed with temporally distinct promoter constructs. 


\section{Acknowledgments}

This work was supported by Award Numbers GM49734 and GM103390 from the National Institute of General Medical Sciences. The content is solely the responsibility of the authors and does not necessarily represent the official views of the National Institute of General Medical Sciences or National Institutes of Health. We thank Dr. Ann Toth (Department of Molecular Biology, University of Wyoming) for measuring the viabilities of the insect cells transformed with the $i e 1,39 \mathrm{~K}, \mathrm{p} 6.9$, and polh promoter constructs at various times after baculovirus infection in response to a question raised during the first round of review of this manuscript.

\section{Abbreviations}

$\begin{array}{ll}\text { AcMNPV } & \text { Autographa californica multicapsid nucleopolyhedrovirus } \\ \mathbf{3 9 K} & \text { baculovirus delayed early gene } \\ \text { hr5 } & \text { homologous region } 5 \\ \text { ie1 } & \text { baculovirus immediate early gene } \\ \text { p6.9 } & \text { baculovirus late gene } \\ \text { polh } & \text { baculovirus very late gene } \\ \text { SEAP } & \text { secreted alkaline phosphatase }\end{array}$

\section{References}

Aumiller JJ, Mabashi-Asazuma H, Hillar A, Shi X, Jarvis DL. A new glycoengineered insect cell line with an inducibly-mammalianized protein $N$-glycosylation pathway. Glycobiology. 2012; 22:417428. [PubMed: 22042767]

Carson DD, Guarino LA, Summers MD. Functional mapping of an AcNPV immediately early gene which augments expression of the IE-1 trans-activated 39K gene. Virology. 1988; 162:444-451. [PubMed: 3277328]

Chazenbalk GD, Rapoport B. Expression of the extracellular domain of the thyrotropin receptor in the baculovirus system using a promoter active earlier than the polyhedrin promoter. Implications for the expression of functional highly glycosylated proteins. J Biol Chem. 1995; 270:1543-1549. [PubMed: 7829482]

Davis TR, Trotter KM, Granados RR, Wood HA. Baculovirus expression of alkaline phosphatase as a reporter gene for evaluation of production, glycosylation and secretion. Nat Biotechnol. 1992; 10:1148-1150.

Friesen, PD. Regulation of baculovirus early gene expression. In: Miller, LK., editor. The Baculoviruses. Plenum Press; New York: 1997. p. 141-170.

Guarino LA, Smith MW. Nucleotide sequence of the $39 K$ gene region of Autographa californica nuclear polyhedrosis virus. Virology. 1990; 179:1-8. [PubMed: 2219715]

Guarino LA, Summers MD. Functional mapping of a trans-activating gene required for expression of a baculovirus delayed-early gene. J Virol. 1986; 57:563-571. [PubMed: 3944847]

Guarino LA, Summers MD. Nucleotide sequence and temporal expression of a baculovirus regulatory gene. J Virol. 1987; 61:2091-2099. [PubMed: 16789264]

Harrison RL, Jarvis DL. Protein $N$-glycosylation in the baculovirus-insect cell expression system and engineering of insect cells to produce "mammalianized" recombinant glycoproteins. Adv Virus Res. 2006; 68:159-191. [PubMed: 16997012]

Harrison RL, Jarvis DL. Transforming lepidopteran insect cells for continuous recombinant protein expression. Meth Mol Biol. 2007; 388:299-316.

Hegedus DD, Pfeifer TA, Hendry J, Theilmann DA, Grigliatti TA. A series of broad host range shuttle vectors for constitutive and inducible expression of heterologous proteins in insect cell lines.

Gene. 1998; 207:241-249. [PubMed: 9511767] 
Higgins MK, Demir M, Tate CG. Calnexin co-expression and the use of weaker promoters increase the expression of correctly assembled Shaker potassium channel in insect cells. Biochim Biophys Acta. 2003; 1610:124-132. [PubMed: 12586386]

Hillar A, Jarvis DL. Re-visiting the endogenous capacity for recombinant glycoprotein sialylation by baculovirus-infected Tn-4h and DpN1 cells. Glycobiology. 2010; 20:1323-1330. [PubMed: 20574041]

Hollister J, Jarvis DL. Engineering lepidopteran insect cells for sialoglycoprotein production by genetic transformation with mammalian $\beta 1$,4-galactosyltransferase and a2,6-sialyltransferase genes. Glycobiology. 2001; 11:1-9. [PubMed: 11181556]

Hollister JR, Grabenhorst E, Nimtz M, Conradt HO, Jarvis DL. Engineering the protein $N$ glycosylation pathway in insect cells for production of biantennary, complex $\mathrm{N}$-glycans. Biochemistry. 2002; 41:15093-15104. [PubMed: 12475259]

Hollister JR, Shaper JH, Jarvis DL. Stable expression of mammalian beta 1,4-galactosyltransferase extends the $N$-glycosylation pathway in insect cells. Glycobiology. 1998; 8:473-480. [PubMed: 9597545]

Hooft van Iddekinge BJL, Smith GE, Summers MD. Nucleotide sequence of the polyhedrin gene of Autographa californica nuclear polyhedrosis virus. Virology. 1983; 131:561-565. [PubMed: 18639177]

Hopkins R, Esposito D. A rapid method for titrating baculovirus stocks using the Sf-9 Easy Titer cell line. Biotechniques. 2009; 47:785-788. [PubMed: 19852765]

Jarvis DL. Effects of baculovirus infection on ie1-mediated foreign gene expression in stably transformed insect cells. J Virol. 1993; 67:2583-2591. [PubMed: 8474163]

Jarvis DL. Baculovirus-insect cell expression systems. Meth Enzymol. 2009; 463:191-222. [PubMed: 19892174]

Jarvis DL, Fleming JA, Kovacs GR, Summers MD, Guarino LA. Use of early baculovirus promoters for continuous expression and efficient processing of foreign gene products in stably transformed lepidopteran cells. Nat Biotechnol. 1990; 8:950-955.

Jarvis DL, Summers MD. Glycosylation and secretion of human tissue plasminogen activator in recombinant baculovirus-infected insect cells. Mol Cell Biol. 1989; 9:214-223. [PubMed: 2494430]

Jarvis DL, Weinkauf C, Guarino LA. Immediate-early baculovirus vectors for foreign gene expression in transformed or infected insect cells. Prot Expr Purif. 1996; 8:191-203.

Kost TA, Condreay JP, Jarvis DL. Baculovirus as versatile vectors for protein expression in insect and mammalian cells. Nat Biotechnol. 2005; 23:567-575. [PubMed: 15877075]

Kost TA, Ignar DM, Clay WC, Andrews J, Leray JD, Overton L, Hoffman CR, Kilpatrick KE, Ellis B, Emerson DL. Production of a urokinase plasminogen activator-IgG fusion protein (uPA-IgG) in the baculovirus expression system. Gene. 1997; 190:139-144. [PubMed: 9185859]

Lopez MG, Alfonso V, Carrillo E, Taboga O. Trans-complementation of polyhedrin by a stably transformed Sf9 insect cell line allows occ- baculovirus occlusion and larval per os infectivity. J Biotechnol. 2010; 145:199-205. [PubMed: 19896510]

Lu, A.; Miller, LK. Regulation of baculovirus late and very late gene expression. In: Miller, LK., editor. The Baculoviruses. Plenum Press; New York: 1997. p. 193-216.

Passarelli AL, Guarino LA. Baculovirus late and very late gene regulation. Curr Drug Targ. 2007; 8:1103-1115.

Pennock GD, Shoemaker C, Miller LK. Strong and regulated expression of Escherichia coli betagalactosidase in insect cells with a baculovirus vector. Mol Cell Biol. 1984; 4:399-406. [PubMed: 6325875]

Rankl NB, Rice JW, Gurganus TM, Barbee JL, Burns DJ. The production of an active protein kinase $\mathrm{C}$-delta in insect cells is greatly enhanced by the use of the basic protein promoter. Prot Expr Purif. 1994; 5:346-356.

Regev A, Rivkin H, Gurevitz M, Chejanovsky N. New measures of insecticidal efficacy and safety obtained with the $39 K$ promoter of a recombinant baculovirus. FEBS Lett. 2006; 580:6777-6782. [PubMed: 17141223] 
Rohrmann, GF. Baculovirus Molecular Biology. 2. Bethesda (MD): National Center for Biotechnology Information (US); 2011. [Internet]Available from : http://www.ncbi.nlm.nih.gov/books/ NBK49500/

Smith GE, Summers MD, Fraser MJ. Production of human beta interferon in insect cells infected with a baculovirus expression vector. Mol Cell Biol. 1983; 3:2156-2165. [PubMed: 6318086]

Sridhar P, Hasnain SE. Differential secretion and glycosylation of recombinant human chorionic gonadotropin (beta hCG) synthesized using different promoters in the baculovirus expression vector system. Gene. 1993; 131:261-264. [PubMed: 8406020]

Summers, MD.; Smith, GE. Tx Ag Expt Stn Bull No 1555. 1987. A manual of methods for baculovirus vectors and insect cell culture procedures.

Toth AM, Geisler C, Aumiller JJ, Jarvis DL. Factors affecting recombinant Western equine encephalitis virus glycoprotein production in the baculovirus system. Prot Expr Purif. 2011; 80:274-282.

Wilson ME, Mainprize TH, Friesen PD, Miller LK. Location, transcription, and sequence of a baculovirus gene encoding a small arginine-rich polypeptide. J Virol. 1987; 61:661-666. [PubMed: 3543402] 


\section{Highlights}

Systematically assessed utility of all four temporal classes of baculovirus promoters.

Only immediate early promoter provided constitutive expression in transformed cells.

Baculovirus infection of transformed cells activated all four promoters.

Delayed early promoter provided highest levels virus-inducible protein production.

Demonstrates utility of delayed early promoter for insect host cell engineering. 


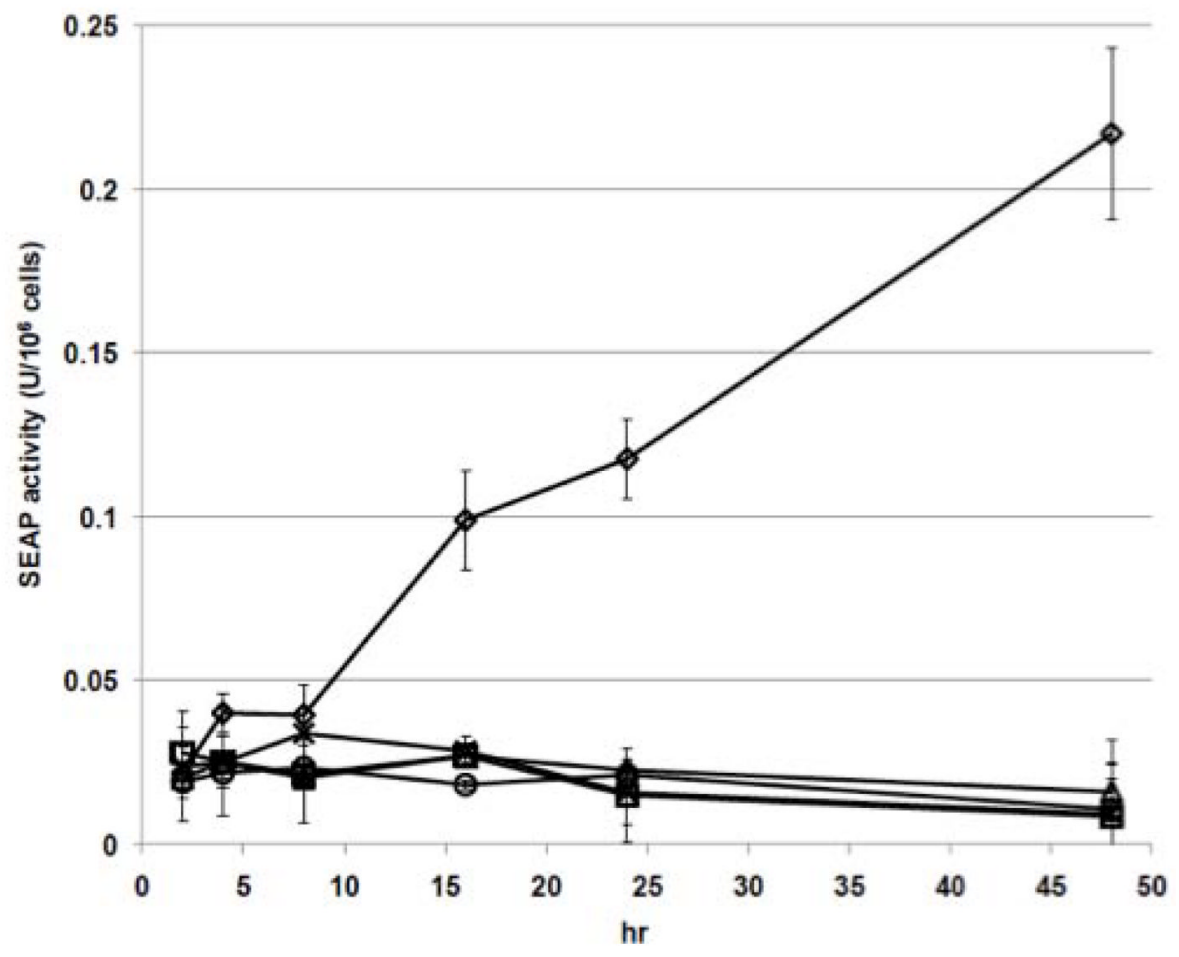

Fig. 1.

Recombinant SEAP production by insect cells transformed with each expression construct. Sf9 cells were transformed with ie1 $(\diamond), 39 \mathrm{~K}(\Delta)$, p6.9 $(\times)$, or polh $(\bigcirc)$ expression constructs, as described in Materials and methods. Parental ( $\square$ ) and transformed Sf9 cell cultures were then set up in parallel and samples were removed at various times, used to produce cell-free supernatants, and the supernatants were assayed for SEAP activity in triplicate, as described in Materials and methods. The plot shows the average SEAP activity/ million cells in the cell free supernatants from each culture after various times of cultivation. The same trends were observed in three independent replicates of this experiment. 
Figure 2A

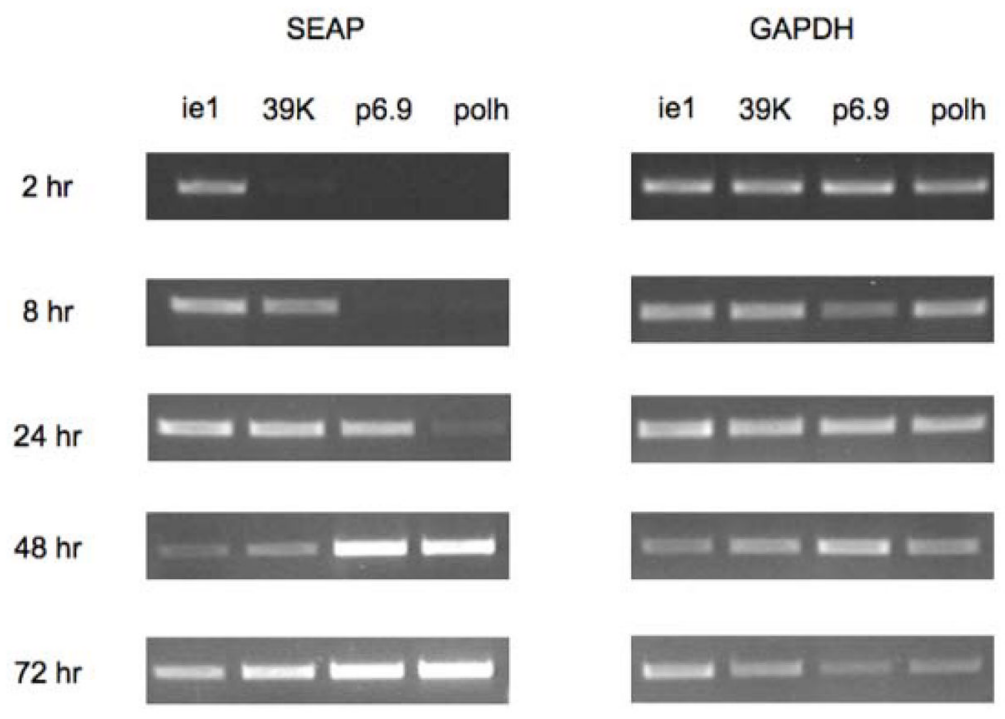

Figure 2B

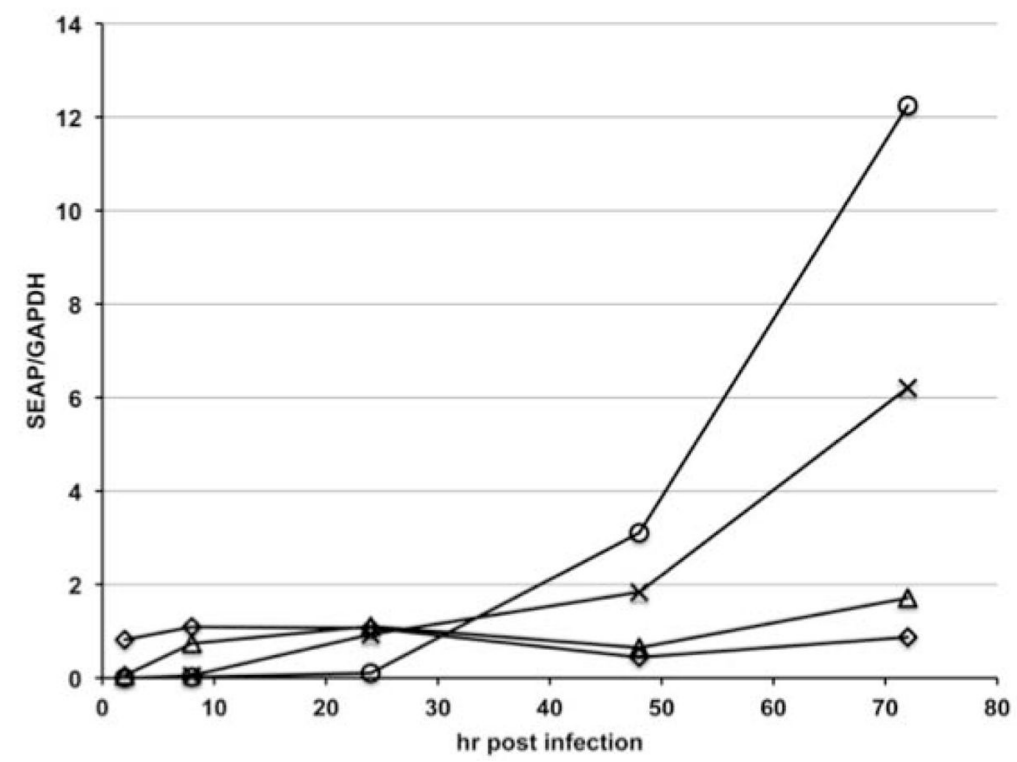

Fig. 2.

Induction of SEAP RNA after baculovirus infection of transformed insect cells. Parallel cultures of Sf9 cells transformed with the indicated expression constructs were infected with Ac $M N P V$, as described in Materials and methods. Samples were removed at various times after infection, used to extract total RNA, and equivalent amounts of each RNA preparation were used for RT-PCR assays, as described in Materials and methods. Preliminary experiments were performed to establish the number of cycles needed to detect SEAP and GAPDH transcripts in the linear range. RT-PCR amplimers produced under those conditions were (A) analyzed on 1\% agarose gels and (B) quantified using a BioRad imaging system, 
as described in Materials and methods. The semi-quantitative results shown in (B) represent the ratio of SEAP:GAPDH RNA detected in Sf9 cells transformed with the ie1 $(\diamond), 39 \mathrm{~K}$ $(\triangle)$, p6.9 $(\times)$, or polh $(\bigcirc)$ expression constructs at various times post-infection. 
Figure $3 \mathrm{~A}$

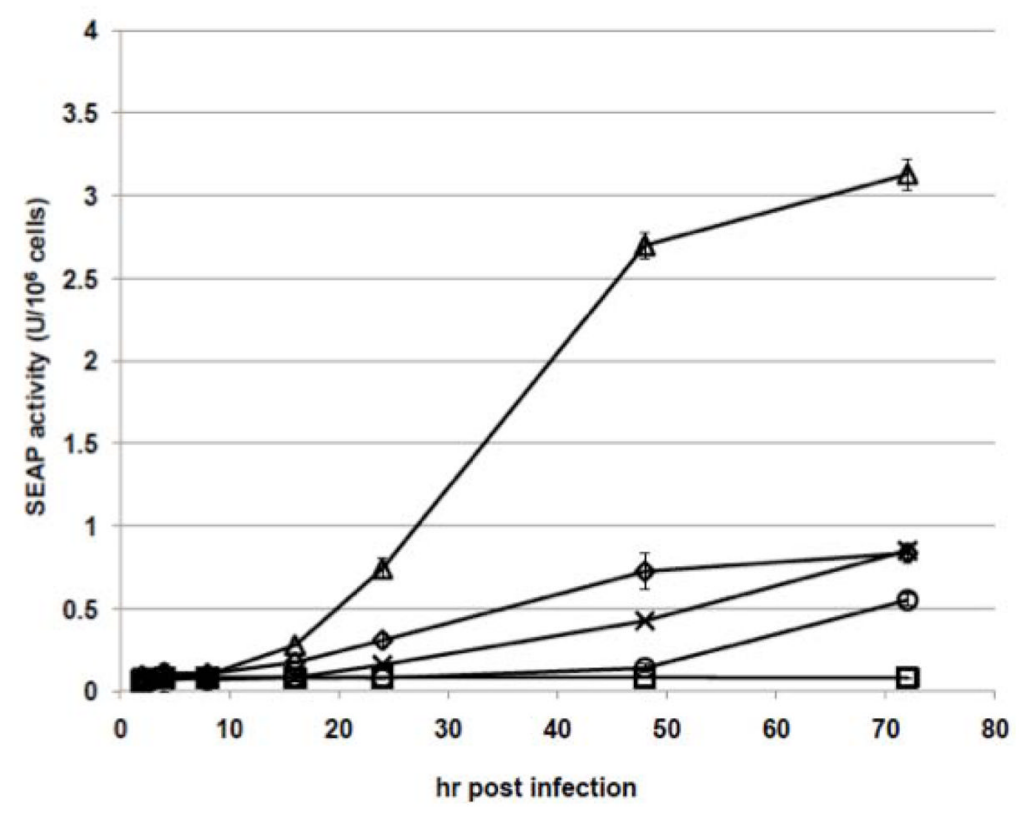

Figure 3B

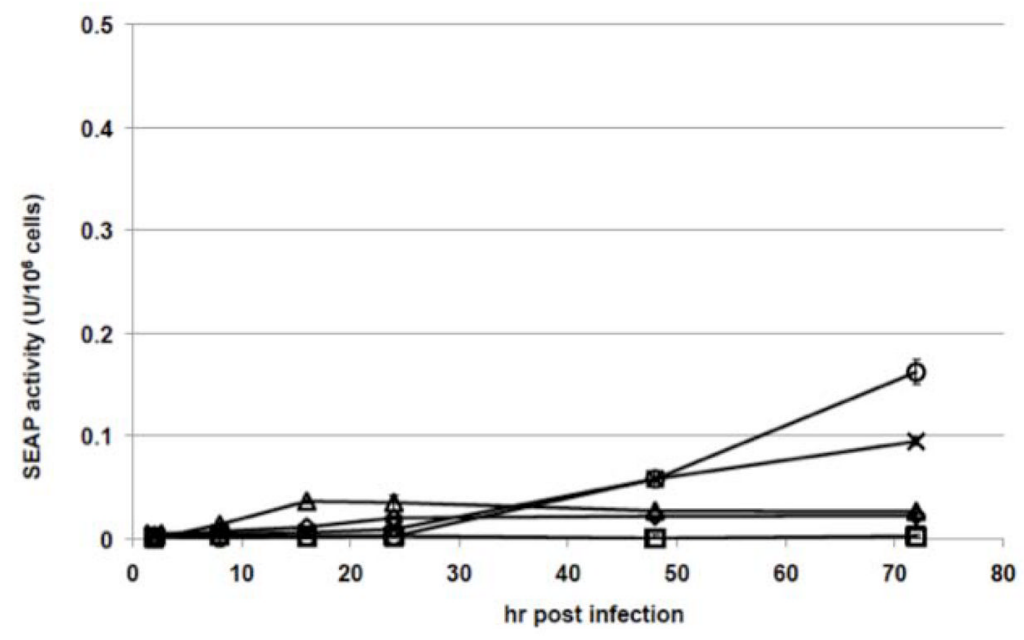

Fig. 3.

Induction of SEAP activity by baculovirus infection of transformed insect cells. Parallel cultures of parental Sf9 $(\square)$ and Sf9 cells transformed with the ie1 $(\diamond), 39 \mathrm{~K}(\Delta), \mathrm{p} 6.9(\times)$, or polh $(\mathrm{O})$ expression constructs were infected with AcMNPV, as described in Materials and methods. Samples were removed at various times after infection, used to produce cellfree supernatants (A) and intracellular protein extracts (B), and each was assayed for SEAP activity in triplicate, as described in Materials and methods. The plots show the average SEAP activity/million cells in the extracellular (A) and intracellular (B) fractions from each culture at various times post-infection, with a $\sim 10$-fold lower $\mathrm{y}$-axis range in the latter. The same trends were observed in three independent replications of this experiment. 


\section{SEAP}

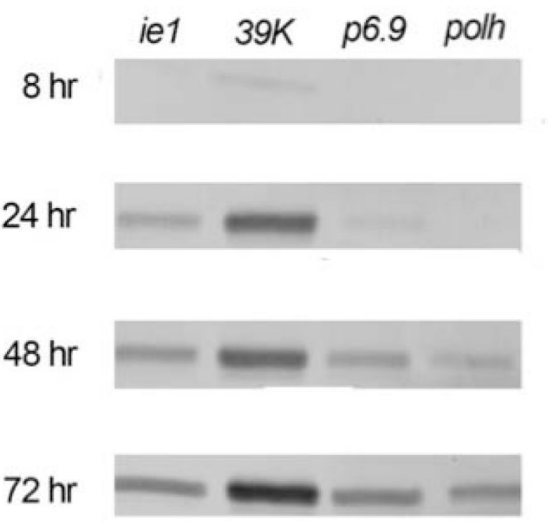

IC SEAP
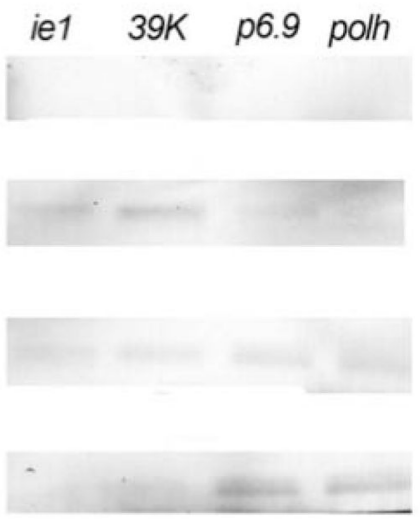

Fig. 4.

Induction of SEAP protein production and secretion by baculovirus infection of transformed insect cells. Parallel cultures of Sf9 cells transformed with the indicated expression constructs were infected with AcMNPV, as described in Materials and methods. Samples containing $1 \times 10^{6}$ cells were removed at various times after infection, used to produce cellfree supernatants and cell extracts, and equivalent amounts of each sample were analyzed by immunoblotting with a SEAP-specific primary antibody, as described in Materials and methods. The results obtained with the cell free supernatants (extracellular fraction; XC SEAP) and cell extracts (intracellular fraction; IC SEAP) are shown. 